\title{
An uncommon sputum material
}

\author{
Giovanni Veloz ${ }^{1 *}$, Michael Cruz ${ }^{2}$, Ricardo Fernandez ${ }^{2}$, Modesto Gonzalez ${ }^{2}$ and Maxim Itkin ${ }^{3}$ \\ ${ }^{1}$ Department of Pulmonary and Critical Care Medicine, San Juan City Hospital, San Juan, Puerto Rico \\ ${ }^{2}$ Department of Pulmonary and Critical Care Medicine, Auxilio Mutuo Hospital, San Juan, Puerto Rico \\ ${ }^{3}$ Department of Radiology, Hospital of the University of Pennsylvania. Interventional Radiology, Philadelphia, PA, USA
}

\section{Introduction}

Plastic bronchitis is a rare disease usually diagnosed clinically by expectoration of branching bronchial casts and chyloptysis, which includes milky-white sputum rich in chyle that may progress to formation of bronchial casts. Chyloptysis can result from abnormal lymphatic drainage and manifest as discharge of chyle into the tracheobronchial tree [1-5]. We present a 49-year-old female with expectoration of branching bronchial cast confirmed via bronchoscopy. Subsequently, magnetic resonance lymphangiogram demonstrated the presence of abnormal pulmonary lymphatic tissue successfully treated with thoracic duct embolization.

\section{Case presentation}

A 49 -year-old female, with past medical history of thoracotomy due to frequent pleural effusions, presented to our institution with a four-month history of dyspnea, dry cough, and episodic expectoration of thick cord-like pink material accompanied by viscous white sputum associated with choking sensation worse at night and in supine position (Figure 1). Physical exam was unremarkable except for decreased breath sounds on basal areas along with bilateral expiratory rhonchi. A Chest CT scan demonstrated small areas of ground glass airspace opacities in the dependent portions of both lungs with concentric thickening of the right pleura (Figures 2 and 3).

Twenty-seven years before our evaluation, the patient reported dyspnea and right-sided pleuritic chest pain during her first pregnancy. Images studies showed right-sided chylothorax treated with chest tube, thoracotomy with decortication, thoracic duct ligation, cisterna chyli ligation and right lower lobe wedge resection, were biopsy revealed chronic interstitial pneumonitis and focal foreign body reaction. At that moment these interventions improved her condition resulting in complete resolution of her symptoms.

After our evaluation, bronchoscopy was remarkable for milkywhite secretions with abundant pale and slightly red, fibrous strands of bronchial casts lodged within the right lower lobe's anterior segments (Figure 4 and 5). Bronchial lavage and aspiration hematoxylin \& eosin stain showed small lymphocytes and macrophages, oil red stain revealed macrophages with lipid droplets (Figures 6 and 7). These findings were suggestive of a chyloptysis that ultimately resulted in subsequent plastic bronchitis.

In view of these findings, a magnetic resonance (MR) lymphangiogram was performed showing abnormal pulmonary lymphatic perfusion with communication between retroperitoneum and pleural spaces, for which she needed a post thoracic duct stenting to improve lymphatic outflow and prevent left side leak (Figure 8). Then underwent embolization of right-side thoracic duct leak that

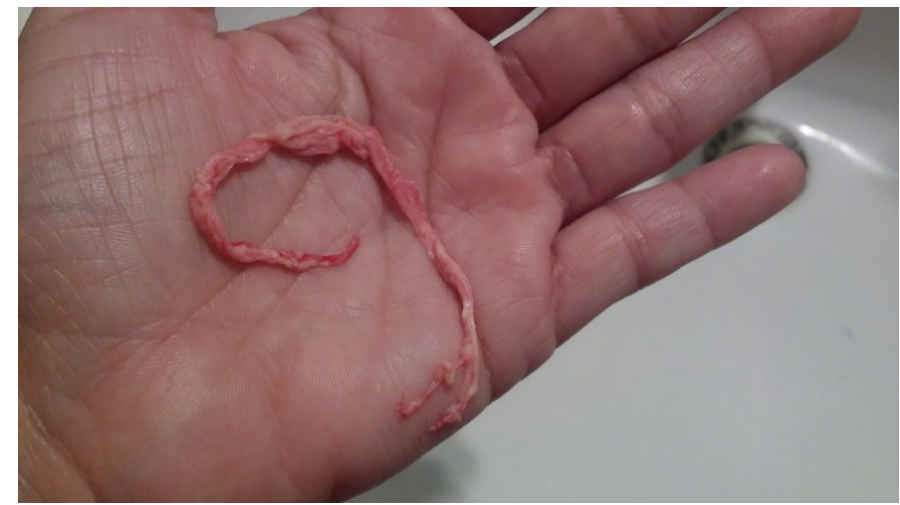

Figure 1. Expectorated bronchial cast

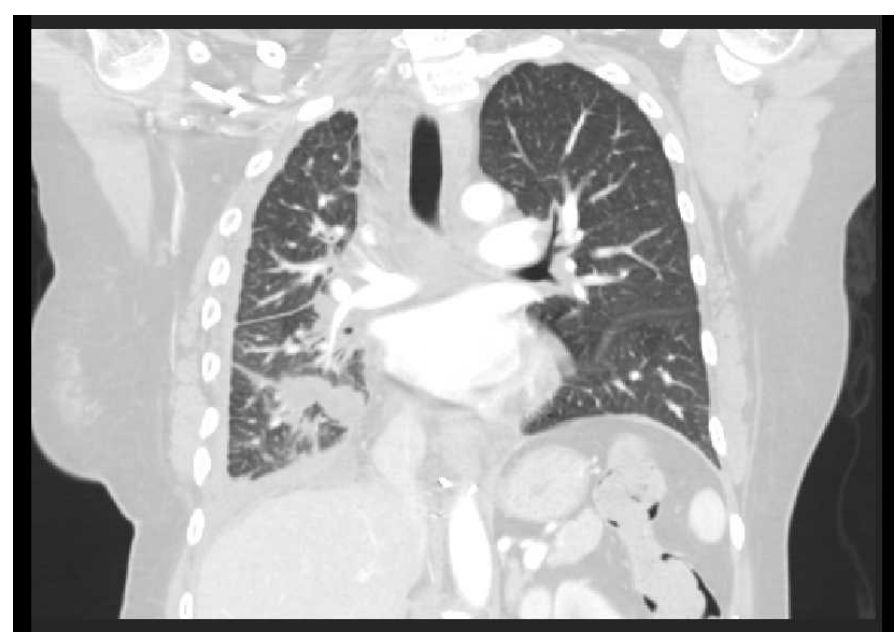

Figure 2. Chest CT scan coronal view showing concentric thickening of the right pleura

was communicating with the right pleural cavity, however, due to an identified persistent leak on MR lymphangiogram, conventional thoracic duct embolization was once again implemented, this time to the mid-mediastinum central thoracic duct abnormality (Figure 9 and10). Results yielded remarkable improvement in condition and no post-procedure complications. Our patient is currently on follow

*Correspondence to: Giovanni Veloz Irizarry, Division of Pulmonary and Critical Care Medicine, San Juan City Hospital, Bo. Monacillos, B-218. San Juan, Puerto Rico, Tel: 787-393-8400, Email: gvelozmd@gmail.com

Received: September 22, 2020; Accepted: October 05, 2020; Published: October 13,2020 


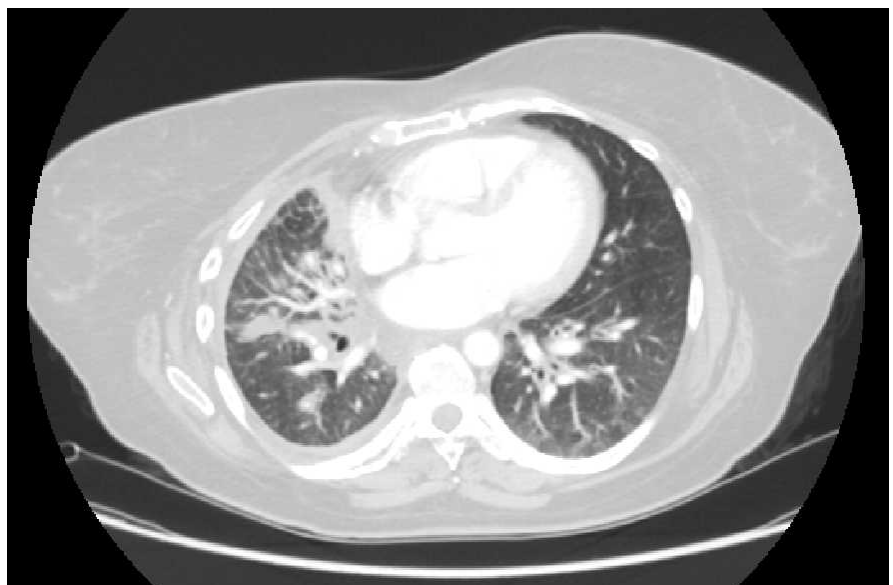

Figure 3. Chest CT scan axial view showing concentric thickening of the right pleura. Additionally, there is concentric thickening of the bilateral pulmonary hilum. Small areas of ground glass airspace opacity are seen in the dependent portions of the bilateral lungs. Additionally, there is diffuse mild superimposed interlobular septal thickening

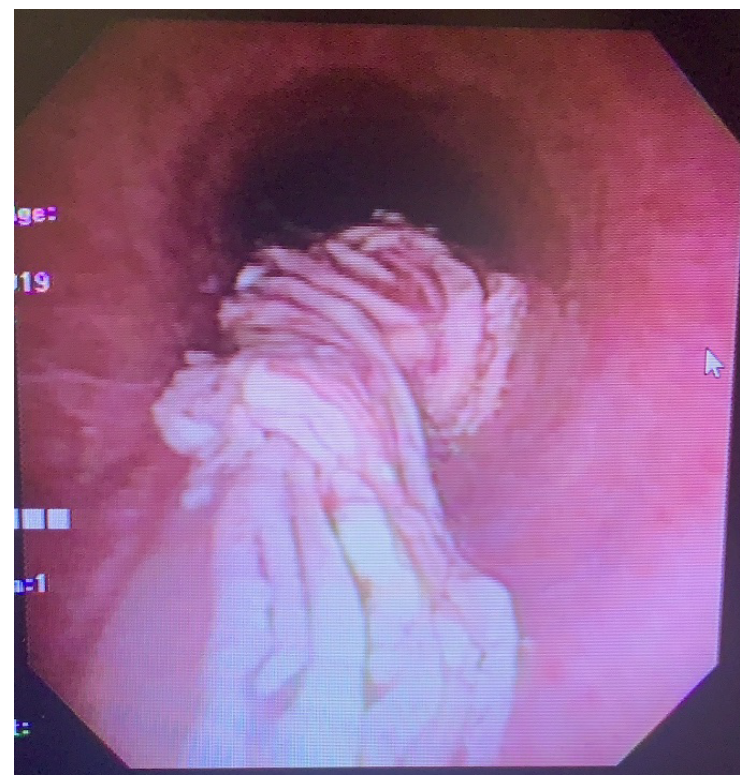

Figure 4. Bronchial cast retrieved during bronchoscopy

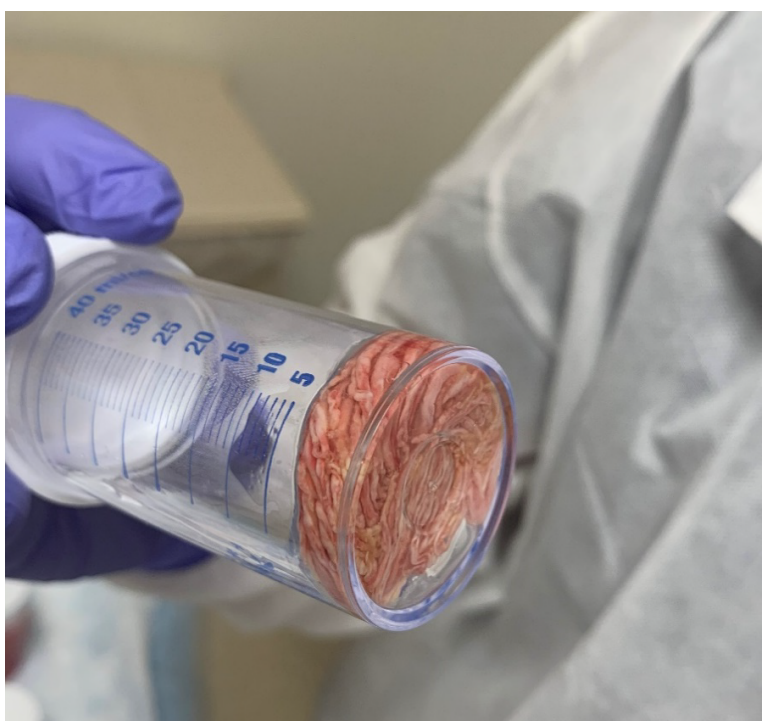

Figure 5. Branching bronchial cast 


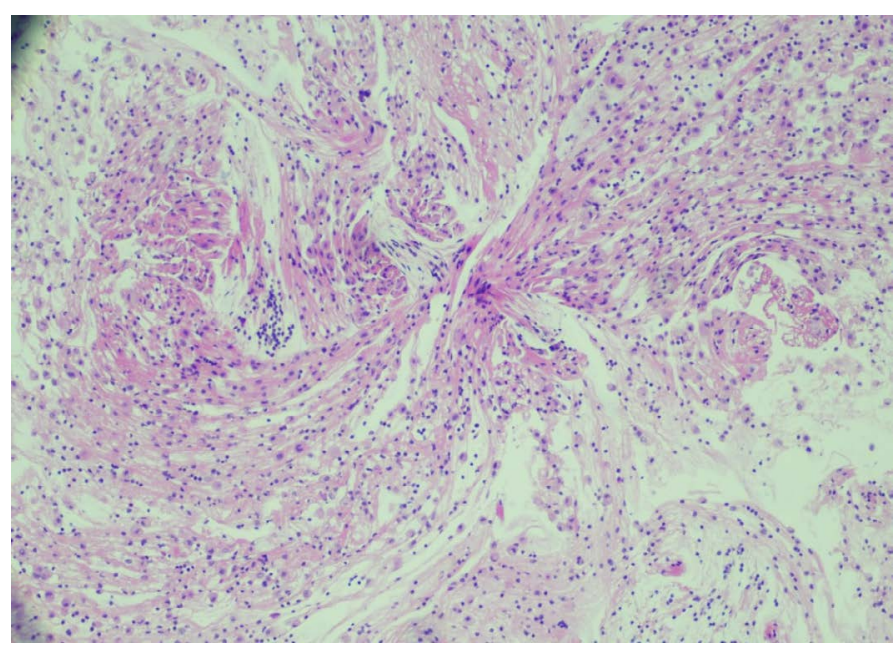

Figure 6. Broncho alveolar lavage hematoxylin \& eosin stain showing small lymphocytes and macrophages

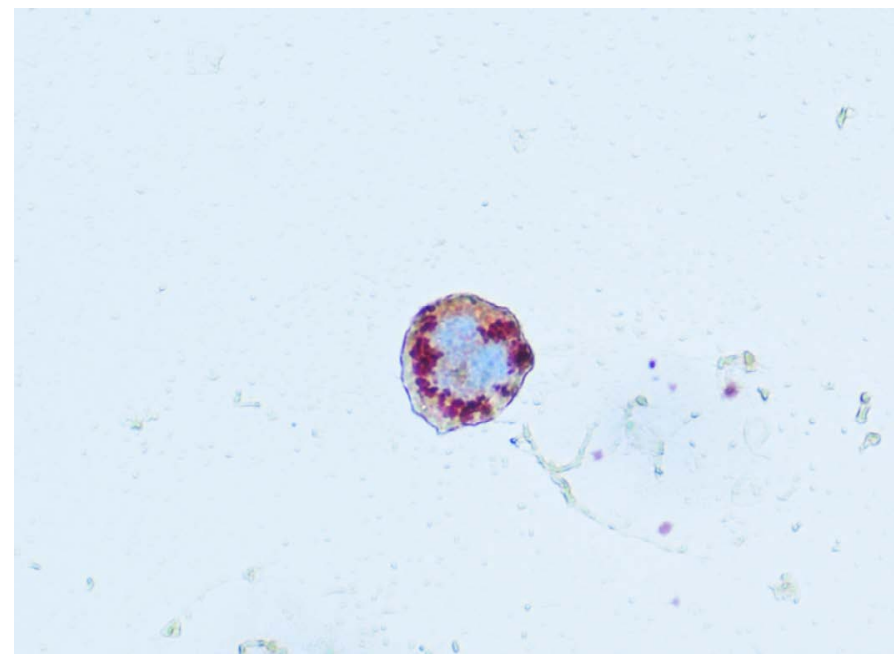

Figure 7. Oil red O showing lipid-laden macrophage

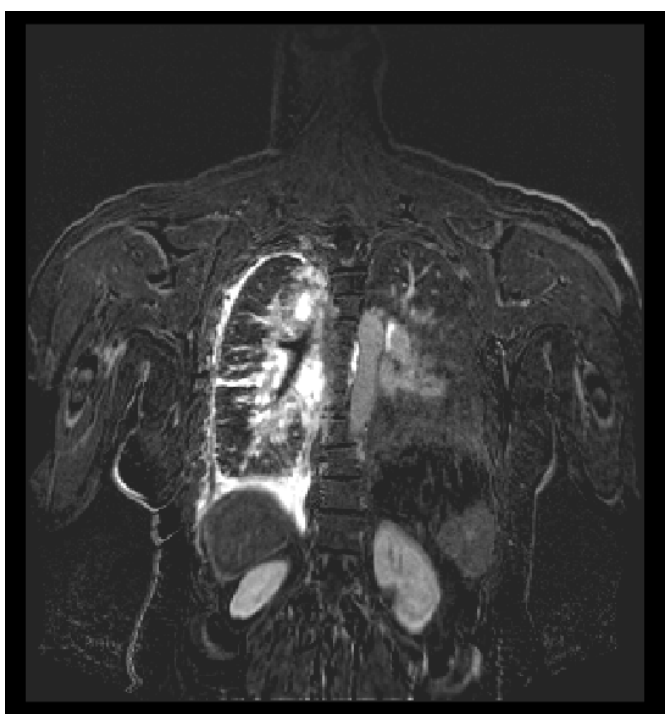

Figure 8. Dynamic contrast enhanced magnetic resonance lymphangiogram show right pleural thickening and interstitial pattern with abnormal lymphatic perfusion of the righ lung, mediastinum and right pleural space. Area of communication between retroperitoneal lymphatics and right pleural space

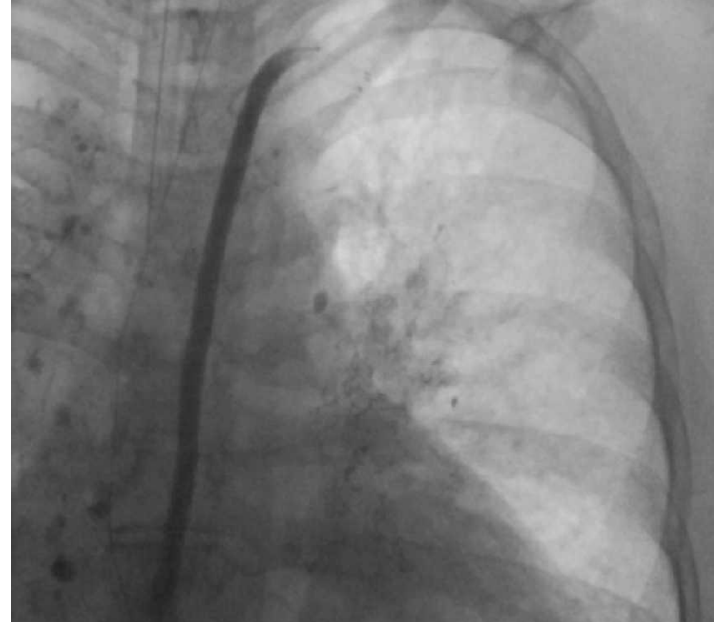

Figure 9. Thoracic lymphangiography with stenting of the central and distal portion of the thoracic duct

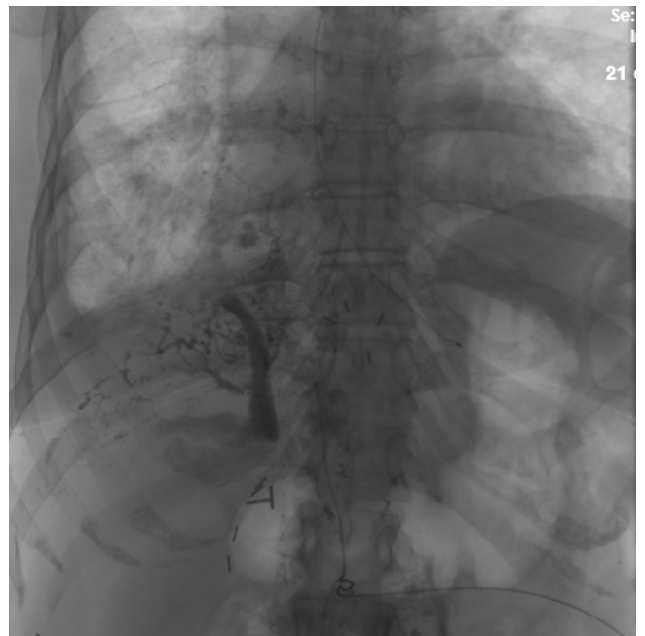

Figure 10. Lymphangiography of the upper abdomen showing multiple abnormal lymphatic channels communicating with the right pleural space

up at our pulmonary clinics in stable condition and has remained asymptomatic.

\section{Discussion}

Plastic bronchitis is a rare disease characterized by the expectoration of bronchial cast, which can vary in size and consistency, varying from small fragmented bronchial cast to branching cast that may occupy the bronchial tree, its most severe form may occlude central airway leading to respiratory failure, often fatally [1-2]. The condition was first defined by Galen (AD 131-200) in which he described "expectorated arteries and veins". Morgagni later postulated that these structures consisted of inspissated bronchial mucus. The characteristic branching mucoid bronchial casts once referred to as fibrinous bronchitis or pseudomembranous bronchitis came to be uniformly known as plastic bronchitis in the 20th century [3]. Plastic bronchitis affects all age groups but is more frequently reported in children. Males and females tend o be equally affected according to most reports, although Eberlein et al. suggested a female predominance [4]. The true prevalence of plastic bronchitis in unknown.

Typically, patients complain of dyspnea, chronic cough, localized wheezing, and respiratory distress, less clinical presentation can vary 
from mild symptoms to life threatening disease. The hallmark is expectoration of branching bronchial casts or direct visualization of these during bronchoscopy, common sign and symptoms include fever and chest pain $[5,6]$. Radiographic evaluation typically shows atelectasis and infiltrates on the ipsilateral side, often with hyperinflation of the contralateral side. Chest CT scan may allow visualization of impacted casts within the major airways. The pathogenesis of plastic bronchitis is unclear. Several theories have been proposed including increased pulmonary venous pressure, increased inflammatory response, trauma to bronchial lymphatic channels, and ischemia of the bronchial tree $[5,6]$. Plastic bronchitis may represent a final common pathway to a variety of insults to the bronchial tree and is considered a rare syndrome due to its cardiac, pulmonary and lymphatic relationship.

Other diseases that have been associated with plastic bronchitis in adults include: asthma, tuberculosis, allergic bronchopulmonary aspergillosis, bronchiectasis, cystic fibrosis, sickle cell anemia, amyloidosis, and rheumatoid arthritis. Plastic bronchitis has been reported in congenital heart disease pediatric population after extra cardiac Fontan operation [4,6]. Magnetic resonance lymphangiogram (MRL) is a technique for specific visualization of central lymphatic system. It involves injection of gadolinium into the inguinal lymph nodes bilaterally followed by image acquisition using magnetic resonance imaging.

Thoracic duct embolization is a well- established minimally invasive procedure developed to treat chylous leaks. The procedure involves diagnostic intranodal lymphangiography followed by percutaneous catheterization of the central lymphatic system and embolization of the thoracic duct proximal to the lymphatic leak $[7,8]$.

Other treatment options that may facilitate cast expectoration include inhaled fibrinolytic agents such as tissue plasminogen activator (t-PA), urokinase and heparin that acts on fibrin, recombinant DNAse (dornase alpha) that acts on cellular material, and inhaled $\mathrm{N}$-acetyl cysteine which appear to be more useful in casts with higher mucin content [9-12].

\section{Conclusion}

This case illustrates a rare presentation of chronic cough, chyloptysis and abnormal lymphatic outflow communication confirmed through direct visualization via bronchoscopy. Afterwards, MRL revealed abnormal pulmonary lymphatic flow that was successfully treated with thoracic duct stent and lymphatic embolization. As described by Grey and colleagues, [7] occlusion of the thoracic duct may be associated with collateral flow of chylous into the peribronchial lymphatics in infants with chylothorax. Similarly, this case correlates with Grey's report which ma entail another etiology, not previously described in adult population presenting with plastic bronchitis. Current understanding of this disease and its management has only been documented in case reports. As a result, diagnosis and treatment of plastic bronchitis can be challenging. Chest physicians must be aware of rare and unusual diseases such as this case with the goal of acquiring adequate work up and definitive diagnosis in order to provide a successful treatment as well as a safe outcome monitored through follow up.

\section{Declaration of interest}

None

\section{References}

1. Madsen P, Shah S, Rubin B (2005) Plastic bronchitis: New insights and a classification scheme. Paediatr Respir Rev 6: 292-300. [Crossref]

2. Liston SL, Proto D, Siegel LG (1986) Plastic bronchitis. Laryngoscope 96: 1347-1351. [Crossref]

3. Leggat PO (1954) Plastic bronchitis. Dis Chest 26: 464-473. [Crossref]

4. Eberlein MH, Drummond MB, Haponik EF (2008) Plastic bronchitis: a management challenge. Am J Med Sci 335:163-169. [Crossref]

5. Cajaiba MM, Borralho P, Reyes-Mugica M (2008) The potentially lethal nature of bronchial casts: plastic bronchitis. Int J Surg Pathol 16: 230-232. [Crossref]

6. A. Bowen (1985) Plastic bronchitis: large, branching, mucoid bronchial casts in children. Am. J. Roentgenol 144: 371-375.

7. Gray M, Kovatis KZ, Stuart T, Enlow E, Itkin M, et al. (2014) Treatment of congenital pulmonary lymphangiectasia using ethiodized oil lymphangiography. J Perinatol 34: 720-722. [Crossref]

8. Itkin M, Mccormack FX, Dori Y (2016) Diagnosis and Treatment of Lymphatic Plastic Bronchitis in Adults Using Advanced Lymphatic Imaging and Percutaneous Embolization. Ann Am Thorac Soc 13: 1689-1696. [Crossref]

9. Rubin BK (2016) Plastic Bronchitis. Clin Chest Med 37: 405-408. [Crossref]

10. Do TB, Chu JM, Berdjis F, Anas NG (2009) Fontan patient with plastic bronchitis treated successfully using aerosolized tissue plasminogen activator: a case report and review of the literature. Pediatr Cardiol 30: 352-355. [Crossref]

11. Wakeham MK, Van Bergen AH, Torero LE, Akhter J (2005) Long-term treatment of plastic bronchitis with aerosolized tissue plasminogen activator in a Fontan patient Pediatr Crit Care Med 6: 76-78. [Crossref]

12. Quasney MW, Orman K, Thompson J, Ring JC, Salim M, et al.(2000) Plastic bronchitis occurring late after the Fontan procedure: treatment with aerosolized urokinase. Crit Care Med 28: 2107-2111. [Crossref]

Copyright: (C2020 Veloz G. This is an open-access article distributed under the terms of the Creative Commons Attribution License, which permits unrestricted use, distribution, and reproduction in any medium, provided the original author and source are credited. 